\title{
SEVENTEEN-YEAR SYSTEMATIC MEASUREMENTS OF DUST AEROSOL OPTICAL PROPERTIES USING THE EOLE NTUA LIDAR SYSTEM (2000-2016)
}

\author{
Ourania Soupiona ${ }^{1}$, Maria Mylonaki ${ }^{1}$, Alexandros Papayannis ${ }^{1}$, Athina Argyrouli ${ }^{1}$, Panayotis \\ Kokkalis ${ }^{1}$ and Georgios Tsaknakis ${ }^{1}$ \\ ${ }^{1}$ National Technical University of Athens, Laser Remote Sensing Unit, Physics Department, Zografou, \\ Greece, apdlidar@central.ntua.gr
}

\begin{abstract}
A comprehensive analysis of the seasonal variability of the optical properties of Saharan dust aerosols over Athens, Greece, is presented for a 17-year time period (2000-2016), as derived from multi-wavelength Raman lidar measurements (57 dust events with more than 80 hours of measurements). The profiles of the derived aerosol optical properties (aerosol backscatter and extinction coefficients, lidar ratio and aerosol Ångström exponent) at $355 \mathrm{~nm}$ are presented. For these dust events we found a mean value of the lidar ratio of $\sim 52 \pm 13 \mathrm{sr}$ at $355 \mathrm{~nm}$ and of $\sim 58 \pm 8 \mathrm{sr}$ (not shown) at $532 \mathrm{~nm}$ (2-4 km a.s.1. height). For our statistical analysis, presented here, we used monthly-mean values and time periods under cloud-free conditions. The number of dust events was greatest in late spring, summer, and early autumn periods. In this paper we also present a selected case study (04 April 2016) of desert dust long-range transport from the Saharan desert.
\end{abstract}

\section{INTRODUCTION}

Dust events occur in the Eastern Mediterranean region mostly from early spring to early autumn, while during winter months dust transport over the area remains quite low as previously shown [1-5]. Aerosol lidar measurements are carried out in Athens since the year 2000. Each year Saharan dust events occurs that heavily influence the atmospheric conditions over the city of Athens. The optical properties of the resulting dust aerosol for the time-period 2000-2016, are presented in this work.

\section{INSTRUMENTATION}

The Raman lidar system (EOLE) of the National Technical University of Athens (NTUA), in the frame of the European Aerosol Research Lidar network (EARLINET) was used to derive the vertical profiles of aerosols over Athens, Greece. The lidar system is located at the Laser Remote Sensing Unit (LRSU) of NTUA $\left(37.9^{\circ} \mathrm{N}, 23.6^{\circ} \mathrm{E}, 200 \mathrm{~m}\right.$ a.s.1.). LRSU is equipped with an advanced 6-wavelength Raman lidar system, with a very recently added (2016), depolarization channel at $355 \mathrm{~nm}$ (Fig. 1), able to perform independent and simultaneous measurements of the vertical profiles of the aerosol backscatter (at 355,532 and $1064 \mathrm{~nm}$ ) and extinction coefficient (at 355 and $532 \mathrm{~nm}$ ). The data processing was based on the Single Calculus Chain (SCC) developed within EARLINET [6] and on manual retrievals. Air-mass back-trajectory analysis from the HYSPLIT and the BSC DREAM models was used to verify the lidar measurements of dust events.

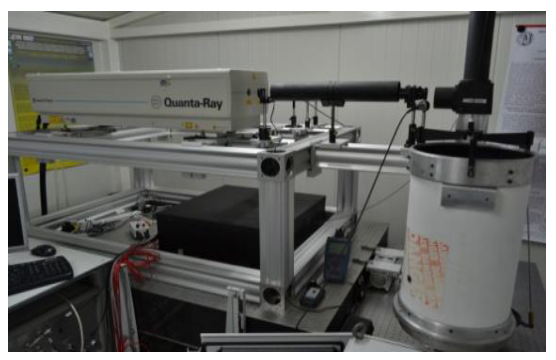

Figure 1. The LRSU multiwavelength Raman lidar (EOLE) system.

\section{METHODOLOGY}

The NTUA aerosol lidar measurements during Saharan dust outbreaks $[1,4]$ are based on early warnings, using forecast model data, provided by the DREAM model [7]. However, the dust lidar measurements are performed only under cloud-free weather conditions. Also, due to the weak Raman signals, the complete set of aerosol products ( 3 backscatter and 2 extinction coefficient profiles) can be derived for tropospheric layers only during nighttime. Thus, the number of the observed dust days is always fewer than the forecasted ones. In Fig. 2 we present the monthly and seasonal distribution of the dust cases percentage of occurrences observed by EOLE, for the period 2000-2016.

In this study the main emphasis has been given on the mean aerosol properties at $355 \mathrm{~nm}$, as the $1^{\text {st }}$ Stokes of the laser radiation at $355 \mathrm{~nm}$ shifted by $\mathrm{N}_{2}$ (at $387 \mathrm{~nm}$ ) was the first Raman channel to be implemented by EOLE in 2003, some years before the implementation of the $2^{\text {nd }}$ Raman channel (at $607 \mathrm{~nm}$ ). Thus, the longest database on the aerosol properties over Athens refers to the $355 \mathrm{~nm}$ channel. We note here, that according to 
Groß et al. [3], during the Saharan Aerosol Long-range Transport and Aerosol-Cloud interaction Experiment (SALTRACE) in Barbados in June and July 2013, the lidar ratio (LR) within the pure dust layer was found to be wavelength independent, with mean values of $53 \pm 5$ $\mathrm{sr}$ at $355 \mathrm{~nm}$.

According to Groß et al., 2015 [3], during the Saharan Aerosol Long-range Transport and Aerosol-Cloud interaction Experiment in Barbados in June and July 2013, the lidar ratio (LR) within the pure dust layer was found to be wavelength independent with mean values of $53 \pm 5 \mathrm{sr}$ at $355 \mathrm{~nm}$.

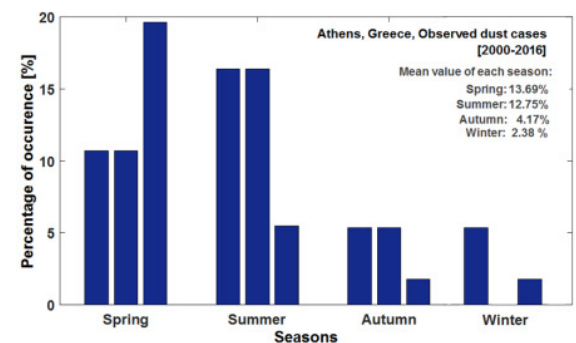

Figure 2. Percentage of occurrence (\%) of the monthly (blue bars) evolution of the mean number of dust cases observed by EOLE over Athens, for the period 2000-2016. Mean values for each season are also mentioned.

\section{STATISTICAL ANALYSIS}

In Fig. 3 (upper and middle graphs) we present the seasonal evolution (from spring to winter) of the vertical profiles of the aerosol optical properties (backscatter- $\beta_{\text {aer }}$ and extinction- $\alpha_{\text {aer }}$ coefficients) at 355 $\mathrm{nm}$, as well as their mean values (red lines) and the corresponding statistical error (red error bars). The seasonal variation of the lidar ratios and their mean values (red lines) are presented in Fig. 3 (lower graph) for the height range between 2 and $4 \mathrm{~km}$, where usually most of the Saharan dust layers are observed [4].

Fig. 4 shows the frequency of occurrence $(\%)$ of the lidar ratio (57 dust cases) values measured at $355 \mathrm{~nm}$ (2-4 km height), where LRs varied from 22 and $77 \mathrm{sr}$; the corresponding statistical mean of LR was $52 \pm 13 \mathrm{sr}$. However, $73 \%$ of the dust cases fall within $40 \mathrm{sr}<\mathrm{LR}<70$ sr, with the most frequent $\mathrm{LR}$ value being between $40-50 \mathrm{sr}(\sim 37 \%$ of the dust cases).

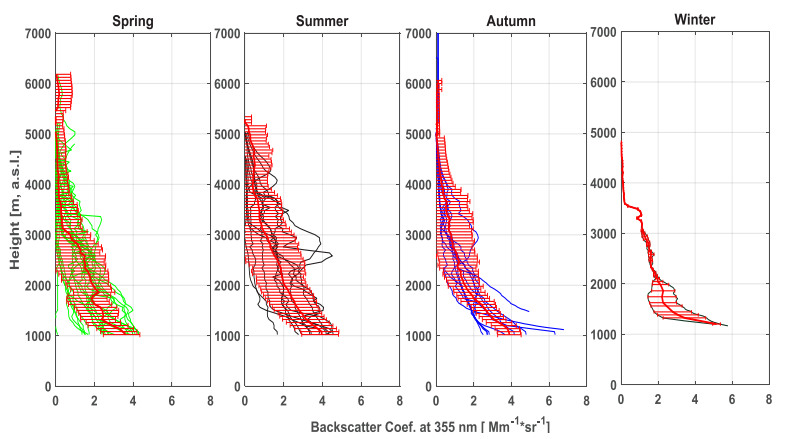

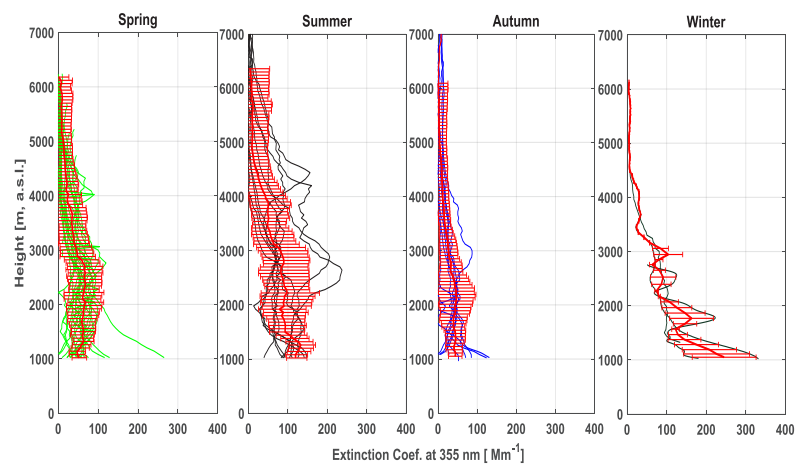

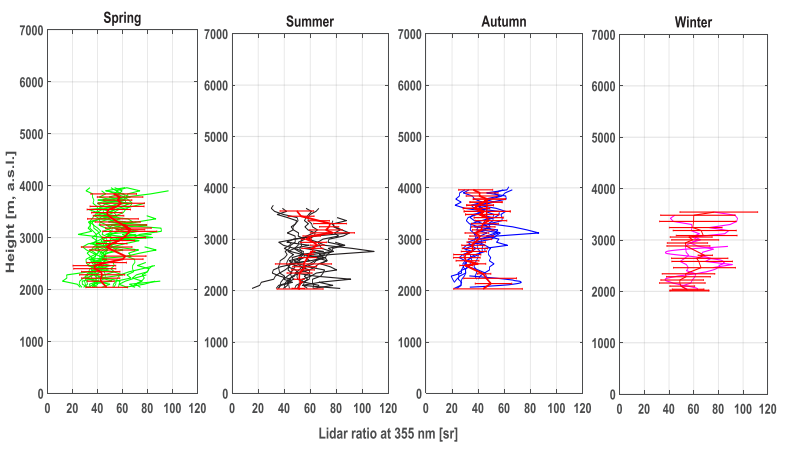

Figure 3. Seasonal variation of the vertical profiles of the aerosol optical properties: backscatter (upper graph), extinction (middle graph) coefficients and lidar ratio (lower graph) at $355 \mathrm{~nm}$, as well as their mean values (red lines) and the corresponding statistical error (red error bars) for 57 dust cases during the period 2000-2016.

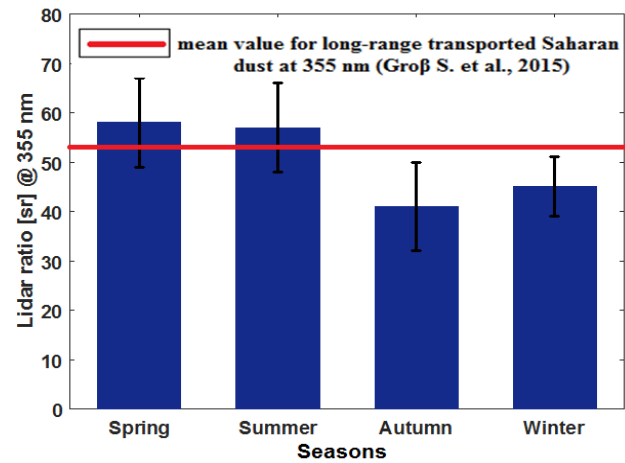

Figure 4. Frequency distribution of the lidar ratio at $355 \mathrm{~nm}$ between 2-4 km a.s.l., as retrieved from 57 observations of dust cases over Athens.

\section{CASE STUDY OF 04 APRIL 2016}

The dust event of 04 April 2016 observed over Athens was forecasted by the BSC-DREAM model for 12:00 and 18:00 UTC (Fig. 5a). The dusty air masses are distinguished by their green-yellow color, spreading from N-NW-W Saharan towards Italy and Greece. The corresponding dust load over Athens was of the order of $0.2 \mathrm{~g} / \mathrm{m}^{2}$. According to the BSC-DREAM forecast, the vertical profile of the dust concentration [shown in 
Fig. 5b, for 12:00 UTC (left) and 18:00 UTC (right)] shows the presence of dust particles from near ground up to $4-4.5 \mathrm{~km}$ height (also between $4.5-6 \mathrm{~km}$ at 18:00 UTC), with maximum mass concentration of $\sim 25$ $\mu \mathrm{g} / \mathrm{m}^{3}$, around $1.5 \mathrm{~km}$ height, indicating an episode of rather low intensity. Indeed, EOLE detected dust layers in the range between 1 and $3 \mathrm{~km}$ and 5.5-7 km height.
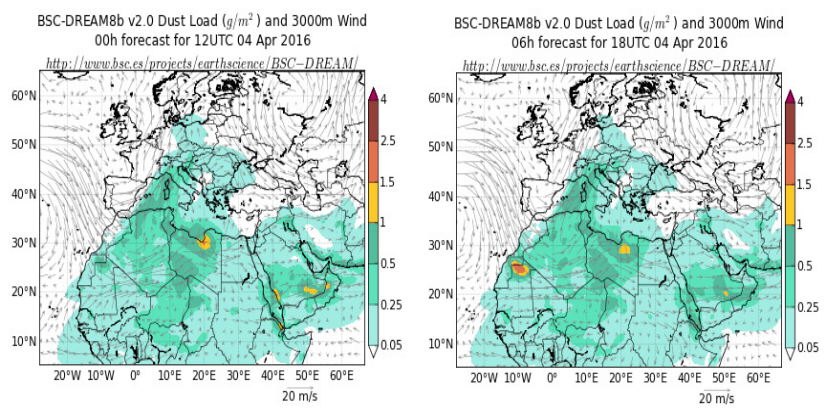

Figure 5a. Dust forecast for 04 April 2016 provided by BSCDREAM model: dust load in $\mathrm{g} / \mathrm{m}^{2}$ for 12:00 UTC (left) and 18:00 UTC (right).
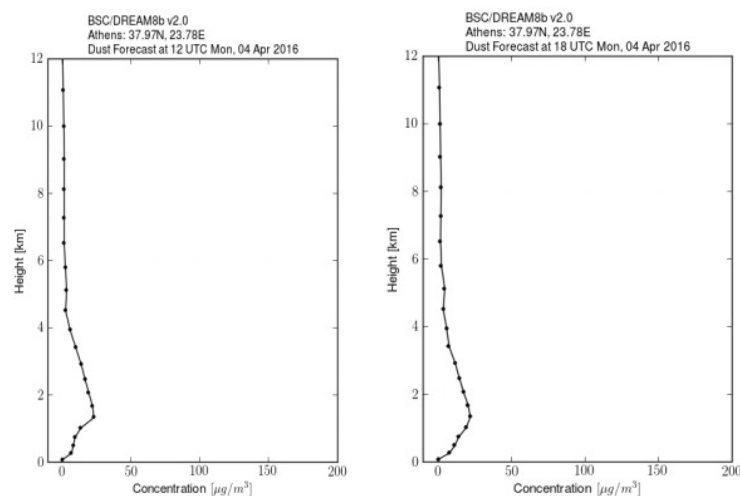

Figure 5b. Dust forecast for 04 April 2016 provided by BSCDREAM model: dust concentration profile in $\mu \mathrm{g} / \mathrm{m}^{3}$ for $12: 00$ UTC (left) and 18:00 UTC (right).

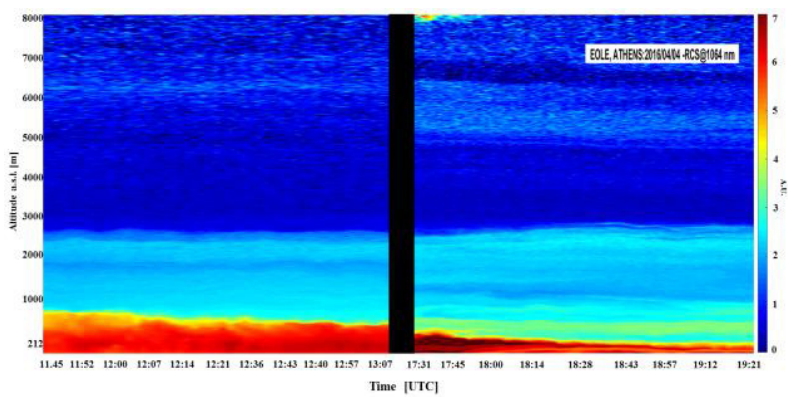

Figure 6. Spatio-temporal evolution of the range-corrected lidar signal at $1064 \mathrm{~nm}$ obtained over Athens on 04 April 2016 (11:45-19:21 UTC).

In Fig. 6 we present the spatio-temporal evolution of the range-corrected lidar signal at $1064 \mathrm{~nm}$ obtained over Athens on 04 April 2016 (11:45-19:21 UTC). The aerosol layers are clearly visible, mainly from 1-3 km and around 5.5-6.5 km height.

Indeed, the aerosol optical properties $\left(\beta_{\mathrm{aer}}\right.$ and the backscatter-related Ångström exponent $\mathrm{AE}_{\mathrm{b}}$ ) obtained by EOLE from 11:45-13:07 UTC (cf. Fig. 7-upper graph) show a thick layer from 1.2 to $3 \mathrm{~km}$ height, with $\mathrm{AE}_{\mathrm{b}}$ (at 532-1064 nm) around 1.1. Similar properties show the aerosol profiles obtained during nighttime from 17:45-19:21 UTC (cf. Fig. 7-lower graph) where the lower aerosol layer re-mains within about the same height range $(1.7-3.5 \mathrm{~km})$ and the $\mathrm{AE}_{\mathrm{b}}(532-1064 \mathrm{~nm})$ is again below1, from 1 to $3.5 \mathrm{~km}$ height (typical for the presence of Saharan dust) [1-3,8].
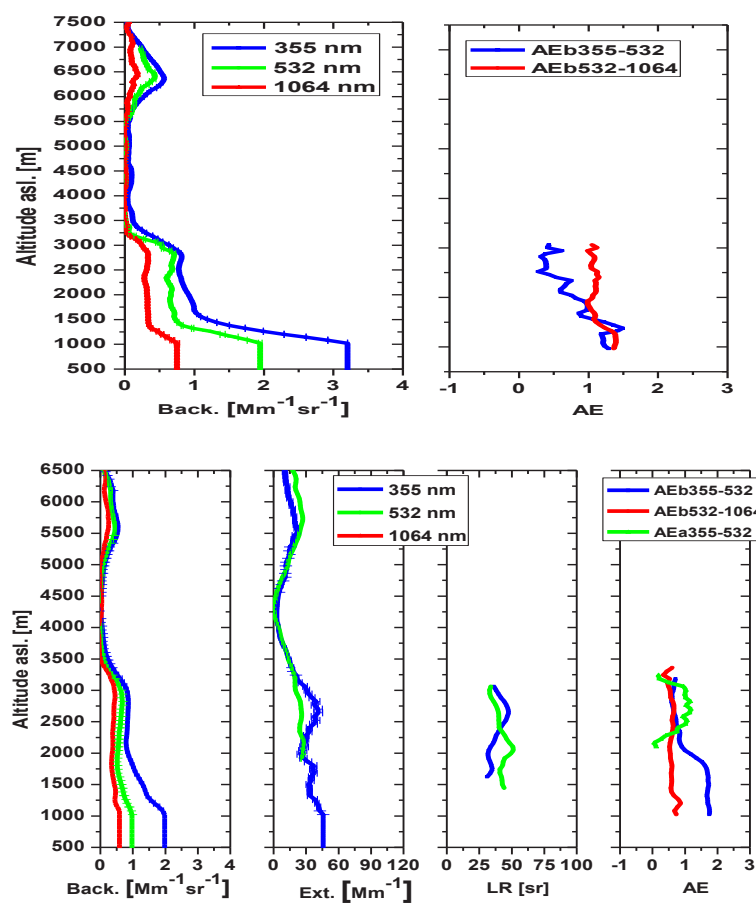

Figure 7. Aerosol optical properties obtained by EOLE at 355, 532, $1064 \mathrm{~nm}$, on 04 April 2016; upper graph: profiles of $\beta_{\text {aer }}$ and $\mathrm{AE}_{\mathrm{b}}(355-532 \mathrm{~nm}$ and 532-1064 nm) (11:45-13:07 UTC); lower graph: profiles of $\beta_{\text {aer }}, \alpha_{\mathrm{aer}}, \mathrm{LR}, \mathrm{AE}_{\mathrm{b}},(355-532$ $\mathrm{nm}$ and 532-1064 $\mathrm{nm})$ and $\mathrm{AE}_{\mathrm{a}}(355-532 \mathrm{~nm})(17: 45-19: 21$ UTC).

Furthermore, the 6-day air mass back trajectories arriving over Athens on 04 April 2016, between 1.8-3 km, are shown in Fig. 8 [for 12:00 UTC (left) and 18:00 UTC (right)] show that the source region of these aerosol layers is the Saharan desert (mainly from Algeria-Tynisia-Libya).

Indeed, SeaWiFS detected the arrival of Saharan dust over Greece on 04 April 2016 (Fig. 9).

Moreover, the AERONET sun photometer of the National Observatory of Athens detected the arrival of 
Saharan dust, showing aerosol optical thickness at 440 nm of $\sim 0.33$ (09:00-15:00 UTC - not shown here).

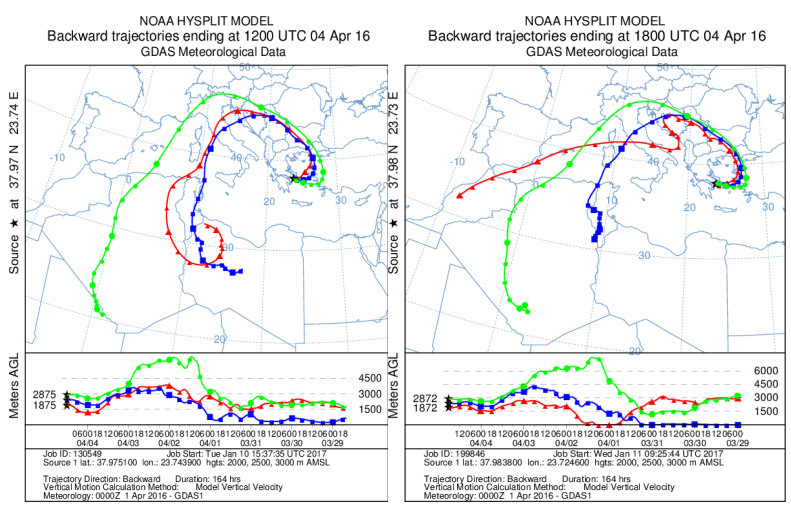

Figure 8. Air mass backward trajectories arriving over Athens on 04 April 2016 at 12:00 UTC (left) and 18:00 UTC (right), based on the NOAA Hysplit model.

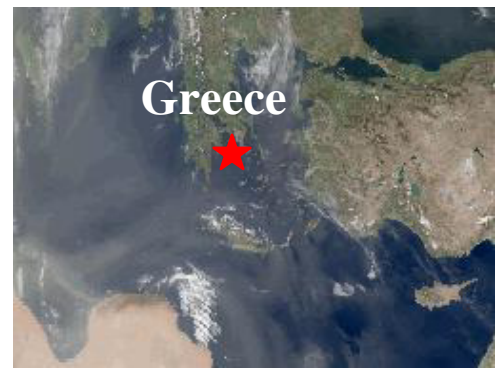

Figure 9. SeaWiFS true color image on 04 April 2016.

Indeed, the true color image provided by the Seaviewing Wide Field-of-view Sensor-SeaWiFS (Fig. 10) on 04 April 2016, clearly shows the desert dust sweeping Greece from SW to the NE (Athens is marked by asterisk).

\section{CONCLUSIONS}

Multi-wavelength aerosol Raman lidar data (57 dust events) have been analyzed for the period 2000-2016, regarding the main aerosol optical properties $\left(\beta_{\mathrm{aer}}, \alpha_{\mathrm{aer}}, \mathrm{LR}, \mathrm{AE}_{\mathrm{a}}\right.$ and $\left.\mathrm{AE}_{\mathrm{b}}\right)$ of Saharan dust particles over the city of Athens. Mean values of $52 \pm 13 \mathrm{sr}$ and $58 \pm 8 \mathrm{sr}$, were found for LR at 355 and $532 \mathrm{~nm}$, respectively.

The height range, where usually most of the layers related to Saharan dust intrusions were observed, was found between 2 and $4 \mathrm{~km}$, while the occurrence of the dust events was greater during spring and summer months.

\section{ACKNOWLEDGMENTS}

The LRSU-NTUA multi-wavelength Raman lidar is founding member of the EARLINET network (www.earlinet.org). The research leading to these results has received funding from the European Union $6^{\text {th }}$ and $7^{\text {th }}$ Framework Programmes (FP6 and FP7 under grant agreement RICA-025991 and no 262254, as well as from the Horizon 2020 ACTRIS research/innovation programme under grant agreement $n^{\circ} 654109$. AP and AA have received funding from the European Union Seventh Framework Programme (FP7/2007-2013): People, ITN Marie Curie Actions Programme (20122016) in the frame of ITaRS, under grant agreement $n^{\circ}$ 289923. The authors gratefully acknowledge the NOAA Air Resources Laboratory for the provision of the HYSPLIT transport and dispersion model and READY website (www.ready.noaa.gov) used in this publication. SeaWiFS image has been provided by NASA GSFC, Ocean Biology Processing Group. The dust forecast and concentration profiles have been provided by BSC-DREAM model (www.bsc.es/ESS/).

\section{REFERENCES}

[1] Papayannis, A., et al., 2005: Measurements of Saharan dust aerosols over the Eastern Mediterranean using elastic backscatter-Raman lidar, spectro-photometric and satellite observations in the frame of the EARLINET project, Atmos. Chem. Phys., 5, 2065-2079.

[2] Balis, D., V. Amiridis, S. Nickovic, et al., 2004: Optical properties of Saharan dust layers as detected by a Raman lidar over Thessaloniki, Greece, Geophys. Res. Lett., 31, L13104, doi:10.1029/2004GL019881.

[3] Groß, S., et al., 2015: Optical properties of long-range transported Saharan dust over Barbados as measured by dualwavelength depolarization Raman lidar measurements, Atmos. Chem. Phys., 15, 11067-11080, 2015.

[4] Papayannis, A., et al., 2008: Systematic lidar observations of Saharan dust over Europe in the frame of EARLINET (2000-2002), J. Geophys. Res., 113, D10204, doi:10.1029/2007JD009028.

[5] Amiridis, V., et al., 2005: Four-year aerosol observations with a Raman lidar at Thessaloniki, Greece, in the framework of EARLINET, J. Geophys. Res., 110, D21203, doi: 10.1029/ 2005JD06190.

[6] d'Amico, G., et al.: EARLINET Single Calculus Chain for automatic lidar data processing: First tests on optical products, 2012: Proc. $26^{\text {th }}$ International Laser Radar Conference, Porto Heli, Greece, 331-334.

[7] Basart, S., et al., 2012: Development and evaluation of the BSC-DREAM8b dust regional model over Northern Africa, the Mediterranean and the Middle East, Tellus, B64, 18539, http://dx.doi.org/10.3402/ tellusb.v64i0.18539.

[8] Papayannis, A., et al., 2012; Optical-microphysical properties of Saharan dust aerosols and composition relationship using a multi-wavelength Raman lidar, in situ sensors and modelling: a case study analysis, Atmos. Chem. Phys., 12, 4011-4032. 